\title{
Circulatory support with a direct cardiac compression device: A less invasive approach with the AbioBooster device
}

\author{
Minoo N. Kavarana, MD, a David N. Helman, MD, ${ }^{a}$ Mathew R. Williams, MD, a Alessandro Barbone, MD, ${ }^{a}$ \\ Juliana A. Sanchez, BA, ${ }^{a}$ Eric A. Rose, MD, ${ }^{a}$ Mehmet C. Oz, MD, ${ }^{a}$ Michael Milbocker, PhD, ${ }^{b}$ and

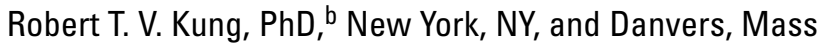

$\mathrm{R}$ efractory cardiogenic shock is an important cause of death in patients after acute myocardial infarction (AMI), therapeutic percutaneous cardiac catheterization, and cardiac surgery. Of the 1.1 million AMI cases annually, $7 \%$ to $10 \%$ have cardiogenic shock, which has a $50 \%$ to $60 \%$ in-hospital mortality. ${ }^{1}$ The value of short-term circulatory support with currently available assist devices is drastically reduced by thromboembolic, hemorrhagic, and infectious devicerelated complications. ${ }^{2}$ The concept of direct cardiac compression (DCC), first introduced in $1965,{ }^{3}$ is simple and elegant, with several advantages over intravascular ventricular assist devices (VAD) in current use. Use of non-blood contacting DCC systems would avoid cardiopulmonary bypass and bleeding complications and would be technically simpler to institute, allowing more widespread use. We evaluated a pneumatic DCC device, the AbioBooster, designed and fabricated by ABIOMED, Inc (Danvers, Mass). This device consists of inflatable polyurethane cylinders wrapped within a silicone-coated polytetrafluoroethylene fabric. Air pumped into and out of the wrap causes contraction and dilatation of its circumference (Figure 1). Twelve sheep studies were performed in nine short-term and three 4-week survival experiments. The effects of the wrap after induced cardiogenic shock (esmolol $\beta$-blockade with norepinephrine) and ventricular fibrillation were characterized. To create a reproducible model of heart failure, we used a continuous infusion of a short-acting $\beta$-blocker, esmolol. An esmolol drip was started at $10 \mathrm{mg} / \mathrm{min}$ and titrated to maintain a descending aortic blood flow at $1.0 \mathrm{~L} / \mathrm{min}$ or less. We evaluated the impact of the device on underlying coronary artery bypass grafts (CABGs) by performing bypasses from the left internal thoracic artery to the left anterior descending artery ( $\mathrm{n}$ $=1)$ or first diagonal artery $(n=2)$ and from the innominate artery to the first obtuse marginal artery $(n=3)$ using a reversed saphenous vein graft before device application.

From the Department of Cardiothoracic Surgery, ${ }^{a}$ Columbia University College of Physicians \& Surgeons, New York, NY, and ABIOMED, Inc, Danvers, Mass.

Received for publication July 26, 2000; accepted for publication March 19, 2001.

Address for reprints: Minoo N. Kavarana, MD, 5800 Arlington Ave, Apartment 22F, Riverdale, NY 10471 (E-mail: mkavarana@hotmail.com).

J Thorac Cardiovasc Surg 2001;122:786-7

Copyright $\odot 2001$ by The American Association for Thoracic Surgery

$0022-5223 / 2001 \$ 35.00+0 \quad \mathbf{1 2 / 5 4 / 1 1 5 9 2 9}$

doi:10.1067/mtc.2001.115929

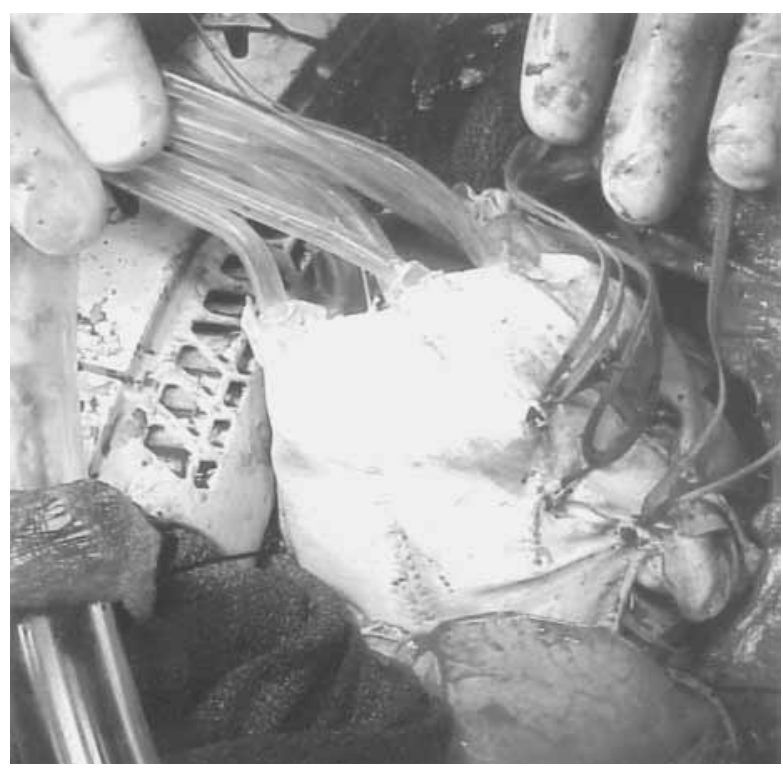

Figure 1. The AbioBooster device applied around the heart.

In the experiments done without CABG, the AbioBooster device was positioned around the heart and fixed in place with glue pads and sutures through a left thoracotomy. The device was activated immediately after implantation and pumping was maintained for 2 hours. Device-tissue interaction and biocompatibility were assessed in 3 long-term experiments during which the device was implanted and left in place for 4 weeks. Shock was induced at weekly intervals to test the device. At the end of 4 weeks, the heart was fibrillated and pumping begun in the asynchronous mode. All animals received humane care in compliance with the "Guide for the Care and Use of Laboratory Animals" prepared by the Institute of Laboratory Animal Resources, National Research Council, and published by the National Academy Press, revised 1996.

The device augmented cardiac output and stroke volume in cardiogenic shock with no alteration of the mean CABG flow in the acute setting (Table 1). During ventricular fibrillation, the device augmented descending aortic blood flow from no detectable flow to $1.5 \pm 0.3 \mathrm{~L} / \mathrm{min}(P=.019)$. At necropsy in 2 long-term experiments, we observed that the wrap was densely adherent to the underlying epicardium. Histologic examination revealed a $1.9-\mathrm{mm}$ mean tissue ingrowth. To prevent this intense reaction, we used a silicone-coated device. At necropsy, the device was removed easily with no adhesions detected. No myocardial contusions were observed, and histologic examination revealed no tissue ingrowth. 
TABLE 1. Device function during shock $(n=9)^{*}$

\begin{tabular}{lcccc}
\hline Parameter & Baseline & Shock & Augmentation & P value \\
\hline Descending aortic flow $(\mathrm{L} / \mathrm{m})$ & $3.0 \pm 1.0$ & $0.8 \pm 0.4$ & $2.9 \pm 0.9$ & .002 \\
Stroke volume $(\mathrm{mL})$ & $26.5 \pm 7.4$ & $8.5 \pm 4.6$ & $25.3 \pm 7.7$ & .004 \\
Mean graft flow $(\mathrm{mL} / \mathrm{min})(\mathrm{n}=3)$ & $31.3 \pm 26.5$ & $28.3 \pm 25.6$ & $37.3 \pm 36.9$ & .74 \\
\hline
\end{tabular}

*Descending aortic flow and stroke volume were evaluated in 9 experiments and graft flow in 3 experiments.

At necropsy in the short-term CABG experiments, the grafts showed no evidence of macroscopic injury and had patent anastomoses.

DCC is a simple and effective method of providing circulatory support but has been underexplored. Intravascular devices have been successfully used for postcardiotomy, medium-term, and long-term support of the failing heart. ${ }^{4}$ However, patients with acute cardiogenic shock or cardiac arrest have a short time frame within which cerebral perfusion must be restored to make patient salvage possible. For this group of patients, intra-aortic balloon pumping or cardiopulmonary bypass has been used with varying success. Although the augmentation of cardiac output provided is often inadequate (10\%-15\% of baseline), inherent hemorrhagic, thromboembolic, and ischemic complications are associated with intra-aortic balloon pumping. ${ }^{5}$ Cardiopulmonary bypass takes longer to implement, requires anticoagulation and cannulation, and is associated with neurologic injury, morbidity, and mortality. ${ }^{6}$ Although previous studies with DCC showed the ability to provide adequate circulatory support in the face of acute cardiogenic shock without blood contact, ${ }^{7,8}$ these studies failed to assess the device effects on previous CABG. As many patients may have had previous revascularization procedures, we evaluated the effect of the device on graft function. We observed no impairment of CABG flow during 2 hours of pumping. At necropsy, the anastomotic sites were patent with no evidence of injury to the conduits. However, the system was carefully placed in the operating room, and kinking may certainly occur with prolonged use.
In conclusion, our initial results indicate that this device provides satisfactory circulatory enhancement in acute cardiogenic shock and is a potentially valuable adjunct in the management of refractory heart failure.

\section{References}

1. Hochman JS, Sleeper LA, Webb JG, Sanborn TA, White HD, Talley $\mathrm{JD}$, et al. Early revascularization in acute myocardial infarction complicated by cardiogenic shock. N Engl J Med. 1999;341:625-34.

2. Wagner WR, Johnson PC, Kormos RL, Griffith P. Evaluation of bioprosthetic valve-associated thrombus in ventricular assist device patients. Circulation. 1993;88:2023-9.

3. Anstadt GL, Baltimore WS, Baue AE. A new instrument for prolonged mechanical massage [abstract]. Circulation. 1965;31(Suppl):II-43.

4. Oz MC, Argenziano M, Catanese KA, Gardocki MT, Goldstein DJ, Ashton RC, et al. Bridge experience with long-term implantable left ventricular assist devices: Are they an alternative to transplantation? Circulation. 1997;95:1844-52.

5. Busch T, Sirbu H, Zenker D, Dalichau H. Vascular complications related to intraaortic balloon counterpulsation: an analysis of ten years experience. Thorac Cardiovasc Surg. 1997;45:55-9.

6. Hill JG, Bruhn PS, Cohen SE, Gallagher MW, Manart F, Moore CA, et al. Emergent applications of cardiopulmonary support: a multi-institutional experience. Ann Thorac Surg. 1992;54:699-704.

7. Anstadt MP, Bartlett RL, Malone JP, Brown GR, Martin S, Nolan DJ, et al. Direct mechanical ventricular actuation for cardiac arrest in humans: a clinical feasibility trial. Chest. 1991;100:86-92.

8. Lowe JE, Anstadt MP, Van Trigt P, Smith PK, Hendry PJ, Plunkett $\mathrm{MD}$, et al. First successful bridge to cardiac transplantation using direct mechanical ventricular actuation. Ann Thorac Surg. 1991;52: 1237-43. 